\title{
Biodiesel Production from Agricultural and Agroindustrial Wastes by Fusarium oxysporum
}

\author{
M.H.Moubasher 1* $^{*}$, M.S.Hamouda ${ }^{1}$, A.M.Tammam 1 and \\ I.F.Tahoun 2 \\ 1 Department of Botany and Microbiology, Faculty of Science, \\ Cairo University, and National institute of Standards, Giza, \\ Egypt
}

\begin{abstract}
THE AIM of the current investigation was to study biodiesel production by Fusarium oxysporum AUMC 3224 cultured on two types of agricultural wastes, the first one called el-ghasheem and the second was wheat straw. In the case of el-ghasheem medium, the maximum lipid production was attained with $125 \mathrm{gl}^{-1}$ ghasheem concentration and $0.1 \mathrm{gl}^{-1} \mathrm{NaNO}_{3}$ for 7 days, at $\mathrm{pH} 5.5$ and temperature $28^{\circ} \mathrm{C}$. Maximum lipid yield was $1.558 \pm 0.003 \mathrm{gl}^{-1}$ lipid weight and $32.44 \pm 0.035 \%$ lipid percentage. In the case of wheat straw, the maximum lipid production was achieved with $5 \mathrm{~g}$ wheat straw, $50 \mathrm{ml}$ of $2 \mathrm{gl}^{-1} \mathrm{NaNO}_{3}$, for 14 days, at $28^{\circ} \mathrm{C}$. Maximum lipid yield was $0.45 \pm 0.005 \mathrm{~g} / \mathrm{L}$ lipid weight and $28.81 \pm 0.305 \%$ lipid percentage. The profile of extracted lipids from F.oxysporum was studied using Fourier transform infrared spectrometer (FTIR) indicating the presence of triglycerides and after transesterification of lipids showed the presence of fatty acid methyl esters. The fatty acids profiles were also determined by gas chromatography (GC) coupled with flame ionization detector and GC-mass spectroscopy. Data revealed the presence of significant amounts of palmitic, oleic, stearic, linoleic and other methyl esters.The results showed that lipids from F.oxysporum was a potential alternative resource for biodiesel production.
\end{abstract}

Keywords : Biodiesel, Fusarium oxysporum, Agricultural wastes, Agroindustrial wastes

Global warming issues have forced exploration of bioenergy as an alternative to oil and coal(La, 2005). The world is facing declining liquid fuel reserves at a time, when energy demand is exploding (Matthew, 2008). Renewable biofuels are needed to displace petroleum derived transport fuels, which contribute to global warming and are of limited availability (Nithya and Velayutham, 2011). One of the most prominent renewable energy resources is biodiesel (Abu Yousuf et al., 2012). Biodiesel, as an alternative fuel for internal combustion engines, is defined as a mixture of monoalkyl esters of long chain fatty acids (FAME) derived from a renewable lipid feedstock via transesterification process, which conform to ASTM D6751 specifications for use in

Corresponding author :- moubasher@sci.cu.edu.eg, moubasher54@hotmail.com 
diesel engines (Ayhan, 2009). General advantages of biodiesel include biodegradability, higher flash point, reduction in exhaust emissions, miscibility in all ratios with petrodiesel, compatibility with the existing fuel distribution infrastructure and inherent lubricity (Knothe, 2008). Biodiesel can be made from almost any naturally occurring oil or fat. Biodiesel has been predominantly (more than $95 \%$ ) produced from edible vegetable oils (biodiesel first generation) all over the world, which are easily available on large scale from the agricultural industry (Gui et al., 2008). If plant oil was used for biodiesel production, the cost of source has account to $70-85 \%$ of the whole production cost (Miao and Wu., 2006). Therefore, it is necessary to explore new raw materials that reduce the biodiesel price without competing with food production (Vicente et al., 2009). In this concern, microbial lipids can represent a valuable alternative feedstock for biodiesel production, and a potential solution for a bio-based economy (Azócar et al., 2010; Abu-Elreesh and Abd-El-Haleem, 2013). Oleaginous microbes (bacteria, fungi and micro algae) are known to accumulate lipids in the form of triacylglycerols (TAGs) (Ratledge and Wynn, 2002).

In this context, fungi are an attractive source of lipids for use in biodiesel synthesis (Ratledge, 1991 \& 2004). Several species of fungi are able to accumulate significant amounts of intracellular lipid (Takeno et al., 2005). This lipid production can be optimized by adding supplementary nutrients to culture media and/or by altering culture conditions during growth (Somasekhar et al., 2003). Fungi are known for their rapid growth with short life cycles, their lack of a need for light energy, easy scalability and the ability to utilize a wide range of carbon sources as lignocellulosic biomass, agro-industrial residues and wastewater (Venkata and Venkata, 2014). Different researches proved that different species belonging to different genera as Asperigullus, Penicillium and Fusarium can accumulate lipid efficiently (Baqir et al., 1997; El-haj et al., 2015) . To reduce the cost of microbial oils, exploring other carbon sources instead of glucose is very important especially for such oils applied to biodiesel production. It was reported that xylose, glycerol, corn straw, molasses, whey and other agricultural and industrial wastes could be used as the carbon sources for microbial oils accumulation (Liang and Jiang, 2013). In the present study, the ability of Fusarium oxysporum Schlechtendal 1824 on the growth on el-ghasheem (agroindustrial) and wheat straw (agricultural) wastes as well as their potential utilities as biodiesel feedstock were investigated. El-ghasheem or El-Reem is agroindustrial foamy liquid resulted from production of cane syrup (Arabic: asl eswed, Literal translation: black honey) in Upper Egypt.This liquid resulted from boiling of sugarcane Juice and represent as a waste where most of it is discarded into a sewage. This el-gasheem is similar to the scum layer which separated during clarification process in cane sugar production. This layer contain sugars, nitrogen compounds and other substances which are important for microbial growth (Madho and Davis, 2008; Thai and Doherty, 2012).

Egypt. J. Bot. 56, №. 3 (2016) 


\section{Material and Methods}

\section{Microorganism and maintenance of the stock culture}

Fusarium oxysporum AUMC 3224 was obtained from Assiut University Mycological center at Assiut, Egypt. Fungal strain was maintained on Czapek's agar slants and stored at $4^{\circ} \mathrm{C}$ with regular transfer at monthly intervals.

\section{Cultivation of fungus}

Firstly, sub-culturing of F.oxysporum was done on Czapek's agar plates which incubated at $28^{\circ} \mathrm{C}$ for 5 days. One centimeter cork porer discs were inoculated to the media of wheat straw (solid media) and el-ghasheem (liquid media)

Using agro-industrial waste products

El-ghasheem and wheat straw were used instead of carbon and nitrogen sources in the ordinary fungal growth media to test the ability of F.oxysporum to accumulate lipids when grown on agro-industrial and agricultural wastes for economical biodiesel production. El-ghasheem used throughout the present work was obtained from traditional cane syrup (asl eswed) factory at El-Minia, Egypt Samples were collected in sterile flasks and kept at $4^{\circ} \mathrm{C}$ for further study. The wheat straw used was obtained from El-Badrsheen farms, Giza, Egypt. The wheat straw were air dried, and used as it is (solid state fermentation).

\section{Wheat straw media preparation}

As mentioned above, wheat straw was used as it is, without any treatment neither chemical nor physical treatments for more economical and safety using of this agricultutral waste. Three types of media prepared using wheat straw, the first one was $5 \mathrm{~g}$ dried wheat straw plus $50 \mathrm{ml}$ of distilled water, the second was $5 \mathrm{~g}$ dried wheat straw plus $50 \mathrm{ml}$ of $\mathrm{NaNO}_{3}\left(1 \mathrm{gl}^{-1}\right)$ and the third type of media was $5 \mathrm{~g}$ dried wheat straw plus $50 \mathrm{ml}$ of $125 \mathrm{gl}^{-1}$ ghasheem. All of these media put in 500 $\mathrm{ml}$ Erlenmeyer flask then autoclaved for $20 \mathrm{~min}$.

\section{El-ghasheem media preparation}

Two types of media were prepared

i- El-ghasheem pure media :- Different concentrations of el-ghasheem were prepared and $100 \mathrm{ml}$ aliquots of the media were placed in $250 \mathrm{ml}$ Erlenmeyer flasks, then autoclaved.

ii- El-ghasheem nitrogen media :- Different concentrations of different nitrogen sources were added to certain concentration of el-ghasheem and $100 \mathrm{ml}$ aliquots of the media were placed in $250 \mathrm{ml}$ Erlenmeyer flasks, then autoclaved .

Optimization of the nutritional, physiological and environmental factors affecting lipid production using el-ghasheem waste product. 
Effect of different concentration of el-ghasheem pure media

Four discs of Fusarium oxysporum cultured on different concentration of elghasheem $\left(40,60,80,100,125,150,200,400\right.$ and $\left.600 \mathrm{gl}^{-1}\right)$ at $28^{\circ} \mathrm{C}, \mathrm{pH} 5.5$ for 14 days to determine the best concentration for fungal growth and production of lipids.

\section{Effect of different types of nitrogen source}

Different types of nitrogen source used to determine the best one for oil production. Sodium nitrate, yeast extract and ammonium sulphate were used, 0.1 $\mathrm{gl}^{-1}$ of each nitrogen source was added to $125 \mathrm{gl}^{-1}$ ghasheem, then 4 discs of F.oxysporum were inoculated and cultured at $28^{\circ} \mathrm{C}, \mathrm{pH} 5.5$ for 14 days.

Effect of addition different concentration of sodium nitrate as external nitrogen source to el-ghasheem

Different concentrations of sodium nitrate was added $\left(0.1,0.2\right.$ and $\left.0.3 \mathrm{gl}^{-1}\right)$ to1 $25 \mathrm{gl}^{-1}$ ghasheem and four discs of F.oxysporum cultured on these media at 28 ${ }^{\circ} \mathrm{C}, \mathrm{pH} 5.5$ for 14 days. The best concentration of sodium nitrate for maximum production of lipids was determined.

\section{Effect of incubation period}

F.oxysporum was cultured and incubated at $28^{\circ} \mathrm{C}$ and $\mathrm{pH} 5.5$ for different time intervals $(5,7,10$ and 14 days $)$

\section{Effect of different $\mathrm{pHs}$}

The effect of different starting $\mathrm{pH}$ values on the lipid production by the fungus was investigated using initially adjusted fermentation medium either with $1 \mathrm{~N} \mathrm{HCl}$ or $\mathrm{NaOH}$ to $\mathrm{pH}$ values ranging from 3.5 to 6.5. All the $\mathrm{pH}$ adjustments were carried out by means of iSTEK $\mathrm{pH}$ meter.

\section{Effect of inoculum size}

In order to test the effect of the inoculums level on cell mass production and lipid accumulation, the sterilized medium was dispended in $250 \mathrm{ml}$ Erlenmeyer flasks (100 $\mathrm{ml}$ each), received different inoculums levels (2,3,4 and 5 discs), inoculated to fermentation medium and incubated at the optimum incubation period.

\section{Effect of different temperatures}

The fungus was cultured and incubated at different temperatures $(20,24,28$ and $32 \pm 1{ }^{\circ} \mathrm{C}$ ) to find out the optimum temperature for the fungal growth and lipid accumulation.

\section{Effect of shaking incubation}

The fungus was cultured and incubated under shaken conditions using a reciprocal shaker with $150 \mathrm{rpm}$ to test the effect of aeration system on the lipid production.

Egypt. J. Bot. 56, No. 3 (2016) 
Optimization of the nutritional, physiological and environmental factors affecting lipid production using wheat straw as waste product

A- Comparison between three types of media which prepared using wheat straw

Four discs of F.oxysporum were inoculated into each type of media and incubated for 14 days at $28{ }^{\circ} \mathrm{C}$ to determine the best media for achieving maximum lipid production

\section{B- Optimum incubation period}

F.oxysporum inoculated to $5 \mathrm{~g}$ straw plus $50 \mathrm{ml} \mathrm{NaNO} 3\left(1 \mathrm{gl}^{-1}\right)$ at $28{ }^{\circ} \mathrm{C}$ for different incubation period 7,14 and 21 days to determine the optimum incubation period for optimum lipid production.

\section{C- Optimum $\mathrm{NaNO}_{3}$ concentration}

F.oxysporum inoculated to $5 \mathrm{~g}$ wheat straw in addition to different concentrations of $\mathrm{NaNO}_{3}$ and incubated at the obtained optimum conditions to determine the best concentration of $\mathrm{NaNO}_{3}$ for preparing wheat straw- $\mathrm{NaNO}_{3}$ media to achieve maximum lipid yield.

Determination of biomass yield (dry weight) of oleaginous microorganism

At the end of the incubation period the cells were harvested by filtration, washed twice with distilled water and oven dried at $70{ }^{\circ} \mathrm{C}$ till constant weight whereby the weight of the dried biomass was calculated.

\section{Extraction of lipid compounds}

Extraction of fungal lipid was carried out according to the method of Folch (Folch et al. , 1957) The freeze-dried mycelia were homogenized and ground well using pestle and mortar with a sufficient amount of chloroform: methanol $(2: 1, \mathrm{v} / \mathrm{v})$ mixtures . This extract was separated by centrifugation and the residue ground again with sufficient fresh mixture of solvents.These extracts (the lipid containing chloroform layers) were collected and then evaporated using rotary evaporator at a temperature $45^{\circ} \mathrm{C}$. before it was weighed for lipid content estimation

Analysis of extracted lipid by Fourier transform infrared spectrometer (FTIR)

The instrument used in this study was TENSOR 27 FTIR, manufactured by Bruker optics, using Attenuated Total Reflectance technique (ATR), The standard sample cell in the FTIR is a Pike Miracle single-bounce attenuated total reflectance (ATR) cell equipped with a ZnSe single crystal. OPUS Data Collection Program (V 1.1 ) is used. the samples analyzed directly without any preparation.

Determination of fatty acids profile by GC-FID and GC-mass

Fatty acid methyl esters (FAMEs) were prepared using sodium methoxide $(0.5 \mathrm{~N})$ as a catalyst. The transesterification was as follows: in a $10 \mathrm{ml}$ test tube,

Egypt. J. Bot. 56, No. 3 (2016) 
$50 \mu \mathrm{l}$ of sample was added followed by $2 \mathrm{ml}$ of sodium methoxide solution and about $0.5 \mathrm{~g}$ anhydrous sodium sulfate. The test tube was capped tightly and shaken vigorously for about $60 \mathrm{~s}$. Then $2 \mathrm{ml}$ of $\mathrm{n}$-hexane was added. Then test tube was firmly capped, shaken vigorously for $5 \mathrm{~min}$. After shaking, $2 \mathrm{ml}$ of saturated potassium chloride was added and left $5 \mathrm{~min}$. for phase separation.

Finally the upper phase (n-hexane) was transferred to GC vials for analysis. The chromatographic analysis of FAMEs was carried out using gas chromatography Agilent $6890 \mathrm{~N}$ equipped with a 7683B automated injector, flame ionization detector (FID) and mass selective detector 5975 inert XL. The chromatographic separation of fatty acids were achieved with a nonpolar column, DB-5MS (60 m, ID $0.25 \mathrm{~mm}$ and film thickness $0.25 \mu \mathrm{m}$ )) from J\&W Scientific (USA). Nitrogen was used as the carrier gas at constant flow $1.0 \mathrm{ml} / \mathrm{min}$. Splitless injection mode was used and the injection performed at $260{ }^{\circ} \mathrm{C}$. The oven temperature was programmed as follows: initial temp. $150{ }^{\circ} \mathrm{C}$, then increased by $4{ }^{\circ} \mathrm{C} / \mathrm{min}$ to $190{ }^{\circ} \mathrm{C}$ and held isothermal for 20 min. at this temperature. it was then, increased by $3{ }^{\circ} \mathrm{C} / \mathrm{min}$ to $220{ }^{\circ} \mathrm{C}$ and held isothermal for $5 \mathrm{~min}$. followed by increase of $4{ }^{\circ} \mathrm{C} / \mathrm{min}$ to $290{ }^{\circ} \mathrm{C}$ and held for $6 \mathrm{~min}$. The mass spectrometer was scanned from $\mathrm{m} / \mathrm{z} 50$ to 500 . The ion source, quadruple and interface temperatures were 230,150 and $300{ }^{\circ} \mathrm{C}$. The chromatographic data was analyzed using Agilent Chemstation Rev. B.02.01-SR1 (260) and MSD Chemstation D.02.00.275. The compounds under study were identified by their retention times and confirmation of identity was performed by mass selective spectrometer (GC-MS).

\section{Statistical analyses}

Statistical analyses were carried out using the SPSS statistical package (SPSS v12). Three replicates for each test were done. Different factors which affect lipid production were compared using one-way analyses of variance (ANOVA) followed by Post Hoc tests. The threshold for significance was 5\%.

\section{Results and Discussion}

Optimization of the nutritional, physiological and environmental factors affecting lipid production using El-ghasheem waste product

\section{Effect of different concentration of el-ghasheem pure media}

$F$. oxysporum was cultured in el-ghasheem pure medium as a sole nutrition medium. Different concentrations of el-ghasheem were used to determine the best concentration for lipid production. Results demonstrated that F.oxysporum could utilize elghasheem only for their growth and lipid production. The highest biomass production was $2.60 \pm 0.016 \mathrm{gl}^{-1}$ and obtained with $150 \mathrm{gl}^{-1} \mathrm{el}$-ghasheem. The highest lipid weight and percentage were $0.495 \pm 0.004 \mathrm{gl}^{-1}$ and $21.2 \pm 0.136 \%$ with $125 \mathrm{gl}^{-1} \mathrm{el}-$ ghasheem. The lipid \% decreased gradually with increasing el-ghasheem concentration above $125 \mathrm{gl}^{-1}$ reaching $10.48 \pm 0.186 \%$ at $600 \mathrm{gl}^{-1}$ (Fig. 1).

Egypt. J. Bot. 56, No. 3 (2016) 


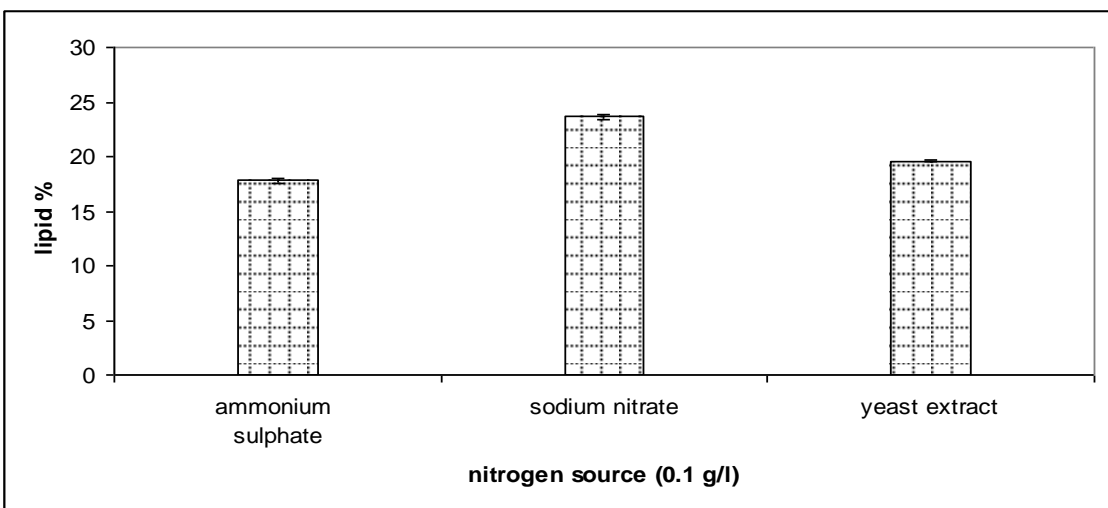

Fig.1. The relation between el-ghasheem concentration and lipid percentage data plotted are means \pm SD of three replicates per test.

Effect of addition different types nitrogen source to el-ghasheem

Huang et al. (1998) reported that organic nitrogenous compounds are good for lipid accumulation, but not for cell growth; on the other hand, inorganic nitrogenous compounds are favorable for cell growth, but not for lipid accumulation. Results from the current study showed that using yeast extract gave the highest biomass dry weight which was $2.493 \pm 0.003$ gl- 1 with lipid weight and percentage of $0.488 \pm 0.003$ and $19.57 \pm 0.095 \%$ respectively. But $\mathrm{NaNO}_{3}$ achieved the highest lipid \% and weight of $23.65 \pm 0.264 \%$ and $0.497 \pm 0.009 \mathrm{gl}^{-1}$ respectively (Fig. 2) with biomass dry weight of $2.10 \pm 0.016 \mathrm{gl}^{-1}$.

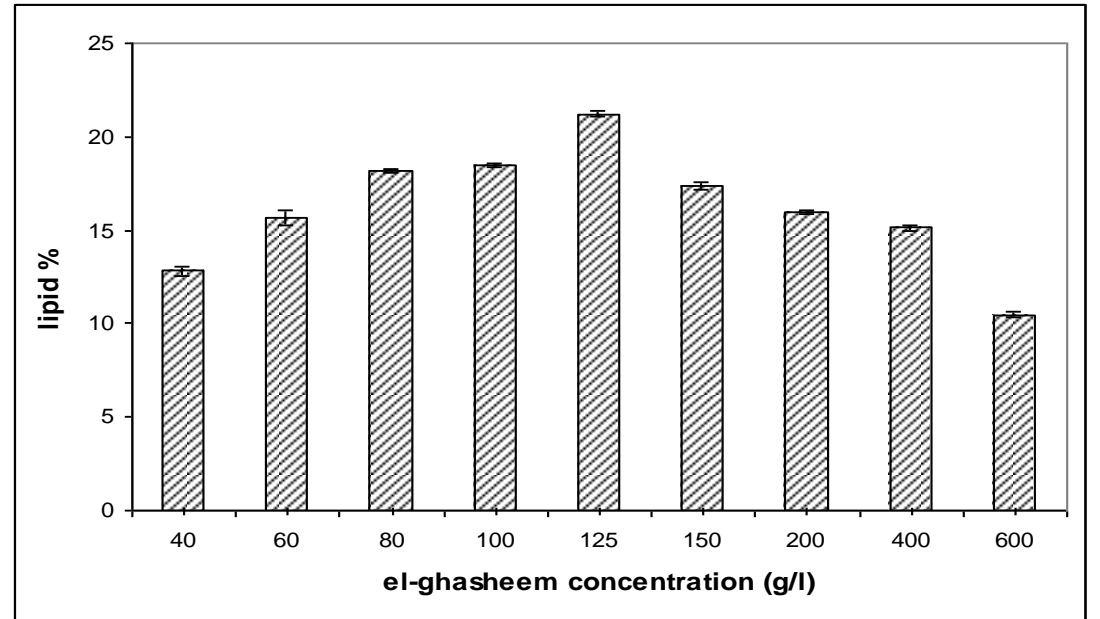

Fig.2. Comparison between different nitrogen sources with lipid percentage data plotted are means \pm SD of three replicates per test.

Egypt. J. Bot. 56, No. 3 (2016) 
Effect of addition different concentration of sodium nitrate as external nitrogen source to el-ghasheem

Lipid accumulation usually occurs in cultures with limited nitrogen and excess carbon (Ratledge and Wynn, 2002). In the present study it was found that $0.1 \mathrm{gl}^{-1}$ $\mathrm{NaNO}_{3}$ achieved the best lipid \% which was $23.65 \pm 0.264 \%$ (Fig. 3) with lipid weight and biomass dry weight $0.497 \pm 0.009$ and $2.10 \pm 0.16 \mathrm{gl}^{-1}$, respectively .

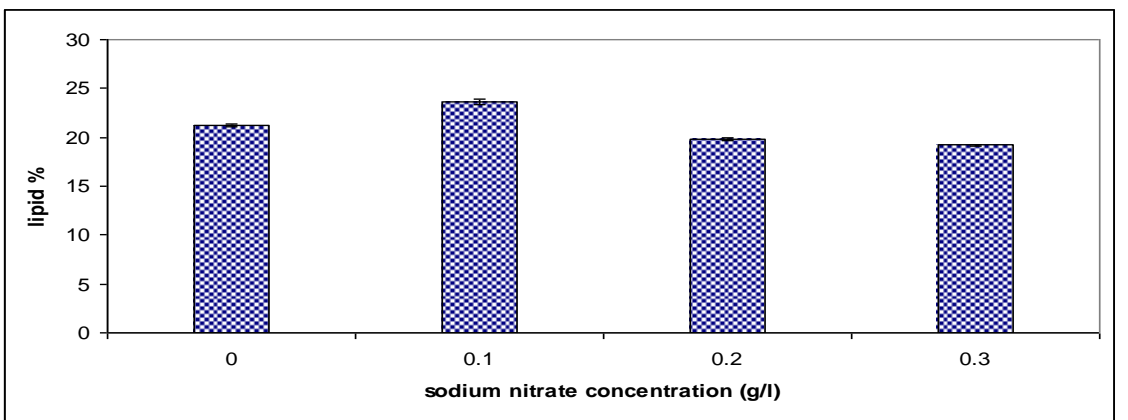

Fig. 3. The relation between $\mathrm{NaNO}_{3}$ concentrations added to el-ghasheem and lipid percentage data plotted are means \pm SD of three replicates per test.

Effect of incubation period

It was noticed that the optimum incubation period for lipid production by $F$. oxysporum was 7 days that led to $0.814 \pm 0.0026 \mathrm{gl}^{-1}$ lipid yield and $31.25 \pm 0.055 \%$ lipid percentage. As shown in the Fig.4. Concerning the biomass produced, it was noticed an increase in biomass production during the time intervals reaching its maximum $\left(2.605 \pm 0.005 \mathrm{gl}^{-1}\right)$ after day 7 . Then, results showed a decrease in biomass and lipid yield. This decrease may be because of the reduction of residual sugars concentration over a period of time intervals which indicates that these sugars were consumed by F.oxysporum to grow and accumulate lipids.

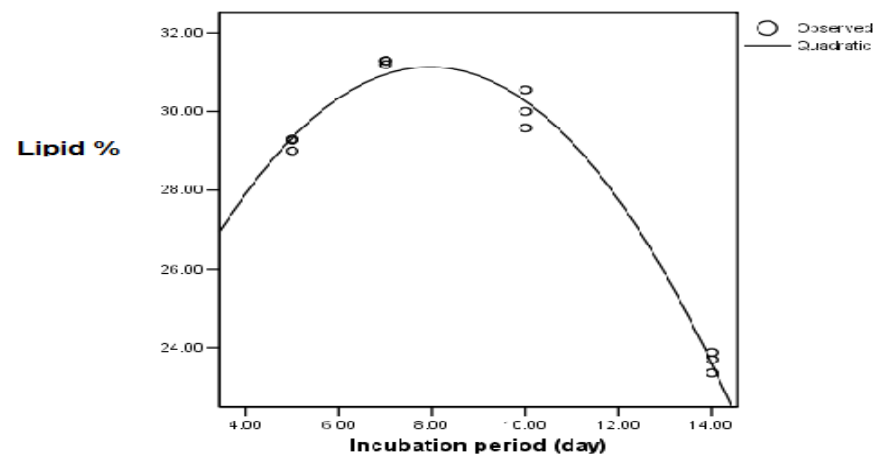

Fig. 4. The relation between different incubation periods and lipid\%. data plotted using regression quadrate mode of three replicates per test. $\left(R^{2}=0.98849\right)$.

Egypt. J. Bot. 56, No. 3 (2016) 
BIODIESEL PRODUCTION FROM AGRICULTURAL AND AGROINDUSTRIAL ... 741

\section{Effect of $p H$ variation}

Results indicated that the best $\mathrm{pH}$ that led to maximum biomass and lipid production was at $\mathrm{pH} 5.5$ which led to biomass dry weight of $2.605 \pm 0.005 \mathrm{gl}^{-1}$, lipid weight of $0.814 \pm 0.0026 \mathrm{gl}^{-1}$ and lipid percentage of $31.25 \pm 0.055 \% \quad$ (Fig. 5). Data showed that there is a net decrease in biomass and lipid production at initial $\mathrm{pH}$ values above and below the $\mathrm{pH}$ range 4.5-5.5 indicating that the tested oleaginous fungus preferred a slight acidic $\mathrm{pH}$ to grow and accumulate lipids which was recorded by many studies (Subramaniam et al., 2010 and Ageitos et al., 2011).

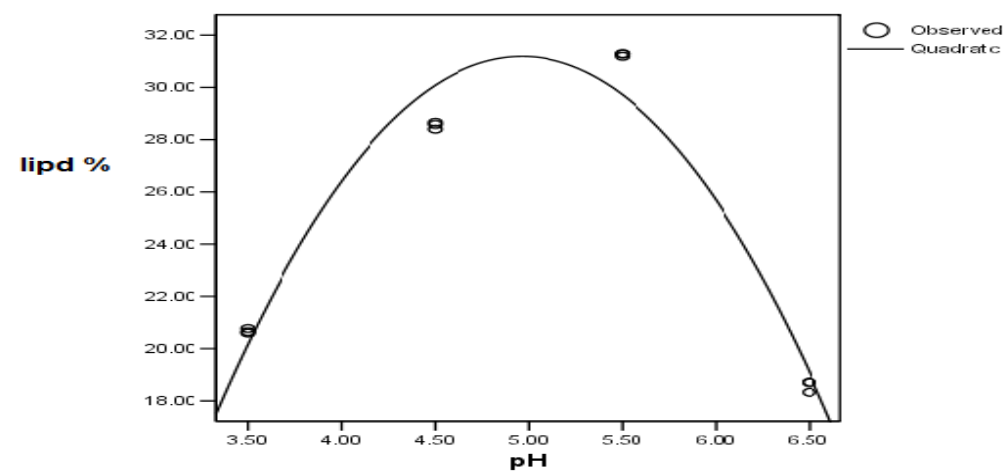

Fig. 5. Effect of different pHs on lipid percentage data plotted using regression quadrate mode of three replicates per test. $\left(R^{2}=0.95276\right)$.

VI- Effect of temperatures variation

It was found that $28 \pm 1{ }^{\circ} \mathrm{C}$ is the optimum temperature for fungal growth and maximum lipid production producing 2.605 $\pm 0.005 \mathrm{gl}^{-1}$ biomass dry weight, $0.814 \pm 0.0026 \mathrm{gl}^{-1}$ lipid weight and $31.25 \pm 0.055 \%$ lipid percentage. There was no growth at $20 \pm 1^{\circ} \mathrm{C}$ and $32 \pm 1^{\circ} \mathrm{C}$ (Fig. 6).

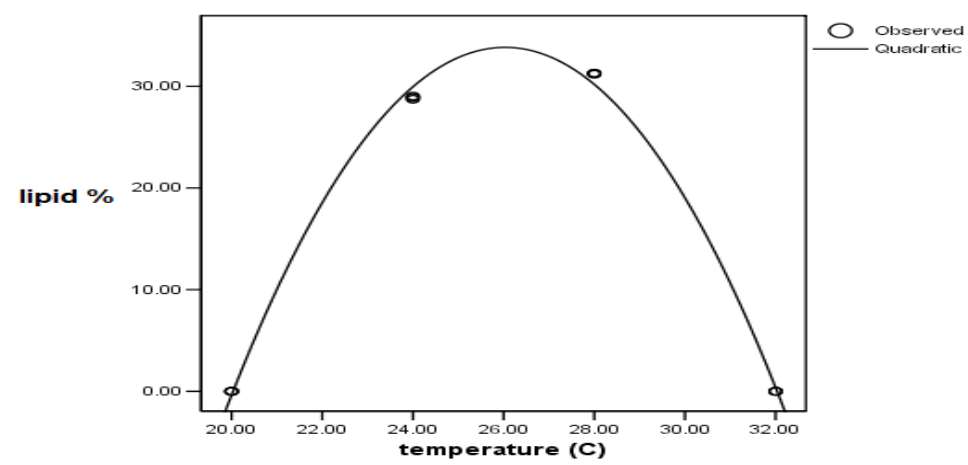

Fig.6. Effect of different temperatures on lipid percentage data plotted using regression quadrate mode of three replicates per test. $\left(R^{2}=0.99719\right)$.

Egypt. J. Bot. 56, No. 3 (2016) 
Effect of inoculum size

Results revealed that the maximum lipid weight was $0.814 \pm 0.0026 \mathrm{gl}^{-1}$ with biomass dry weight of $2.605 \pm 0.005 \mathrm{gl}^{-1}$ which was obtained with inoculum size of 4 discs and led to lipid percentage of about $31.25 \pm 0.055 \%$ (Fig. 7).

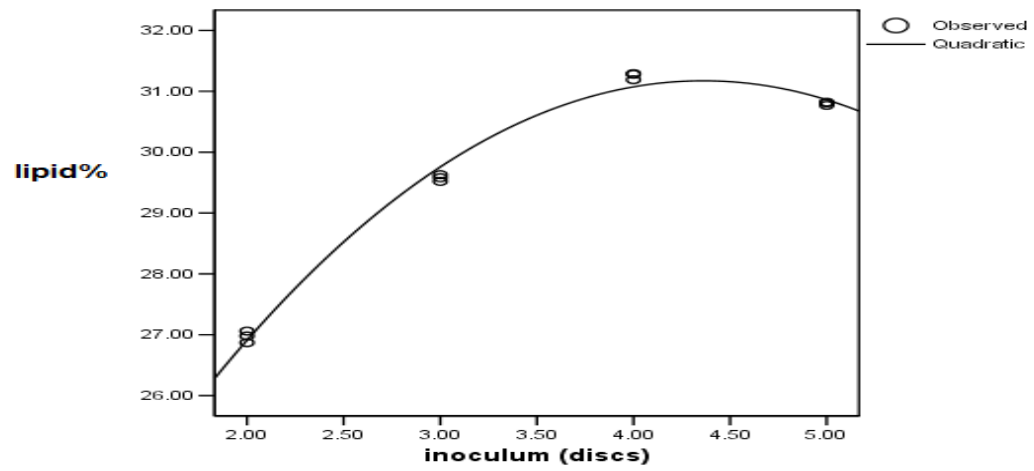

Fig. 7. The relation between inoculum size and lipid percentage data plotted using regression quadrate mode of three replicates per test. $\left(R^{2}=0.99255\right)$.

\section{Effect of shaking incubation}

It is known that shaking of the fungal growth medium during incubation period gives more aeration and help fungal growth, so shaking at $150 \mathrm{rpm}$ with other optimum conditions was used to record the highest lipid production by F.oxysporum. It was found that using shaking at $150 \mathrm{rpm}$ achieved biomass dry weight and lipid production higher than stationary incubation. Aeration system gave $4.803 \pm 0.0036 \mathrm{gl}^{-1}$ biomass dry weight , $1.558 \pm 0.003 \mathrm{gl}^{-1}$ lipid weight and $32.44 \pm 0.035 \%$ lipid percentage while stationary incubation system gave $2.605 \pm 0.0045 \mathrm{gl}^{-1}$ biomass dry weight , $0.814 \pm 0.0026 \mathrm{gl}^{-1}$ lipid weight and $31.25 \pm 0.055 \%$ lipid percentage (Fig. 8 a and b)

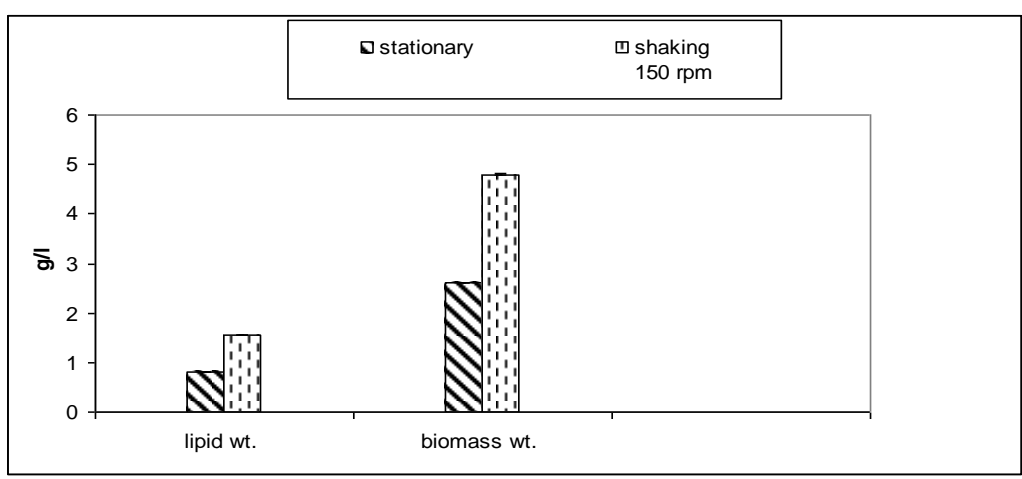

Fig. 8. a. Effect of shaking incubation on biomass and lipid dry weight data plotted are means \pm SD of three replicates per test.

Egypt. J. Bot. 56, No. 3 (2016) 


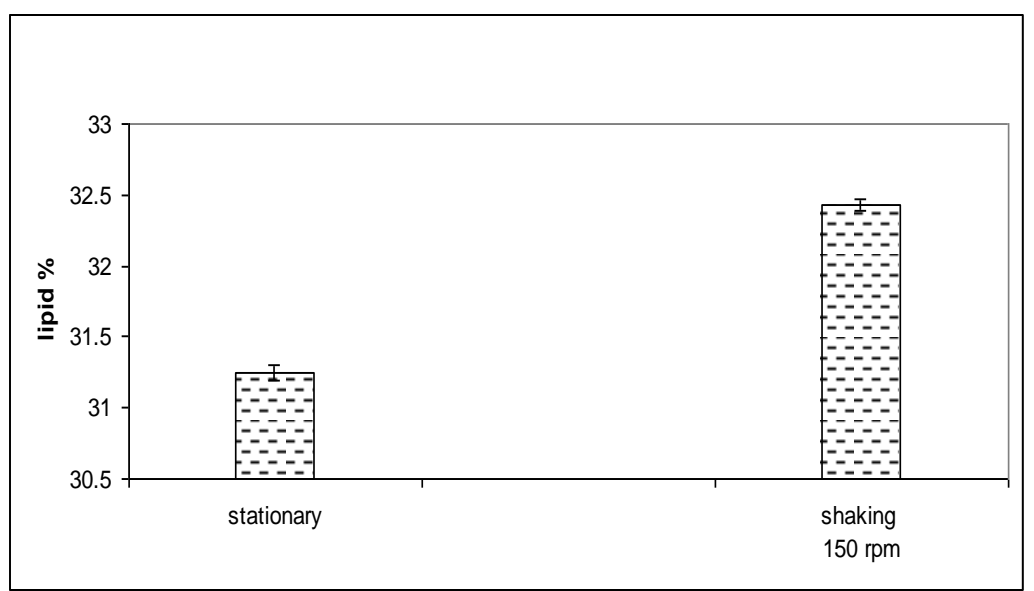

Fig.8.b. Effect of shaking incubation on lipid percentage data plotted are means \pm SD of three replicates per test.

Analysis of variance (ANOVA)

Summary of one-way ANOVA of all factors affecting lipid production using el-ghasheem are shown in Table 1. F-ratios suggest that all the factors had statistically significant effects at a $95 \%$ confidence limit.

TABLE 1. One-way ANOVA summary of factors affecting lipid production in the case of el-ghasheem waste.

\begin{tabular}{|l|l|l|l|l|l|l|}
\hline \multirow{2}{*}{ factor } & \multicolumn{2}{l}{ df } & \multicolumn{2}{l|}{ sum of squares } & \multirow{2}{*}{ Fig. } \\
\cline { 2 - 5 } & $\begin{array}{l}\text { between } \\
\text { groups }\end{array}$ & $\begin{array}{l}\text { within } \\
\text { groups }\end{array}$ & $\begin{array}{l}\text { between } \\
\text { groups }\end{array}$ & $\begin{array}{l}\text { within } \\
\text { groups }\end{array}$ & F-ratio & Sig \\
\hline $\begin{array}{l}\text { El-ghasheem } \\
\text { concentration (g/l) }\end{array}$ & 8 & 18 & 243.225 & 0.756 & 723.947 & .000 \\
\hline $\begin{array}{l}\text { NaNO } \\
\text { el-ghasheem (g/l) }\end{array}$ & 3 & 8 & 35.502 & 0.236 & 401.154 & .000 \\
\hline $\begin{array}{l}\text { Incubation period } \\
\text { (day) }\end{array}$ & 3 & 8 & 101.968 & 0.673 & 403.792 & .000 \\
\hline pH & 3 & 8 & 334.063 & 0.153 & 5812.312 & .000 \\
\hline Inoculum size (discs) & 3 & 8 & 33.243 & 0.032 & 2793.518 & .000 \\
\hline Temperature & 3 & 8 & 2720.739 & 0.051 & 141881.9 & .000 \\
\hline
\end{tabular}


Optimization of the nutritional, physiological and environmental factors affecting lipid production using wheat straw as waste product

A-Comparison between three types of media which prepared using wheat straw

It was found that $\mathrm{NaNO}_{3}$ plus wheat straw media support the best lipid weight of $0.358 \pm 0.004 \mathrm{gl}^{-1}$ and maximum lipid percentage of $23.6 \pm 0.213 \%$ (Fig. 9) compared to both el-ghasheem plus wheat straw and distilled water plus wheat straw media which gave lipid weight of $0.346 \pm 0.002 \mathrm{gl}^{-1}$ and $0.175 \pm 0.005 \mathrm{gl}^{-1}$ respectively with lipid percentage of $11.89 \pm 0.064 \%$ and $17.9 \pm 0.131 \%$ respectively. El-ghasheem gave the best biomass dry weight of $2.908 \pm 0.007 \mathrm{gl}^{-1}$ than both $\mathrm{NaNO}_{3}$ and distilled water which gave biomass dry weight of $1.514 \pm 0.004 \mathrm{gl}^{-1}$ and $0.975 \pm 0.032 \mathrm{gl}^{-1}$, respectively.

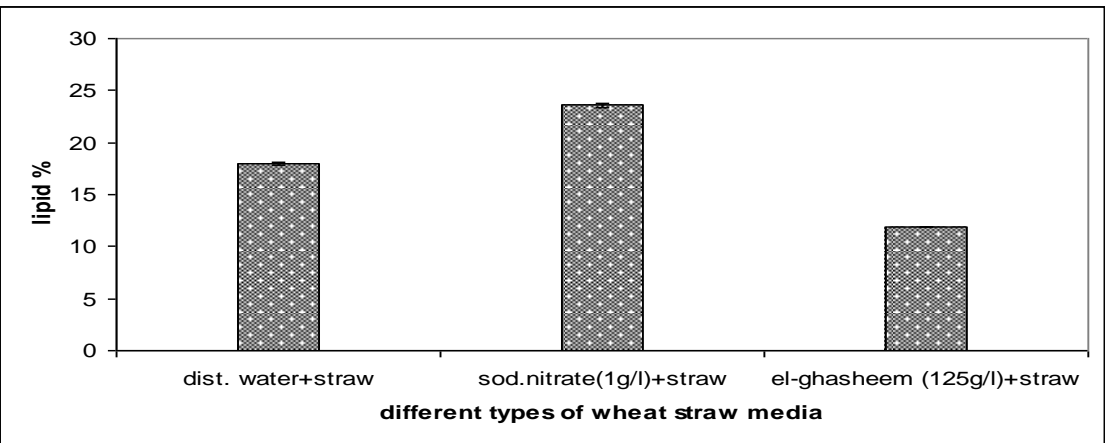

Fig. 9. Comparison between three types of media using wheat straw data plotted are means \pm SD of three replicates per test.

B- Optimum incubation period

It was found that the best incubation period was 14 day which achieved biomass dry weight of $1.514 \pm 0.004 \mathrm{gl}^{-1}$, lipid weight of $0.358 \pm 0.004 \mathrm{gl}^{-1}$ and lipid percentage of $23.62 \pm 0.213 \%$ (Fig. 10) .

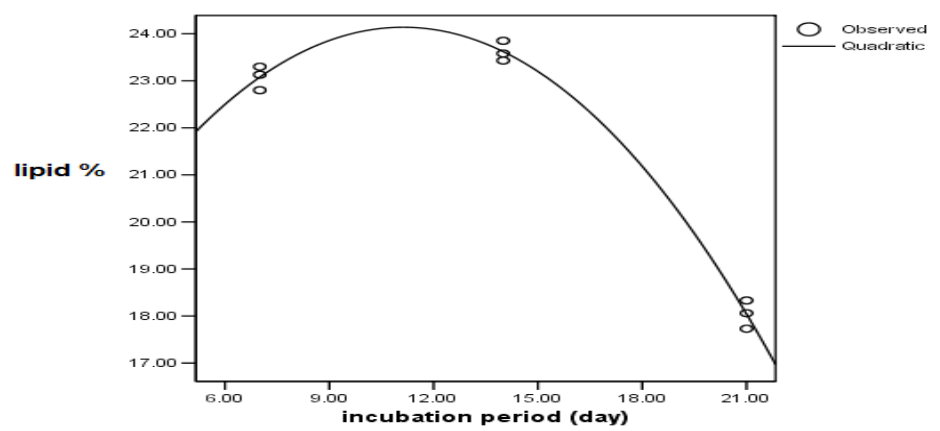

Fig. 10. The relation between incubation period using wheat straw plus $1 \mathrm{gl}^{-1} \mathrm{NaNO}_{3}$ and lipid percentage data plotted using regression quadrate mode of three replicates per test. $\left(\mathbf{R}^{2}=0.99300\right)$.

Egypt. J. Bot. 56, No. 3 (2016) 


\section{C- Optimum $\mathrm{NaNO}_{3}$ concentration}

It was found that $2 \mathrm{gl}^{-1} \mathrm{NaNO}_{3}$ was the best concentration for maximum lipid weight of $0.45 \pm 0.005 \mathrm{gl}^{-1}$ and lipid percentage of $28.81 \pm 0.305 \%$ with biomass dry weight of $1.557 \pm 0.0015 \mathrm{gl}^{-1}$. On the other hand $3 \mathrm{gl}^{-1} \mathrm{NaNO}_{3}$ gave the best biomass dry weight of $1.610 \pm 0.0056 \mathrm{gl}^{-1}$ with lipid weight and percentage of $0.397 \pm 0.0035 \mathrm{gl}^{-1}$ and $24.64 \pm 0.135 \%$ (Fig. 11).

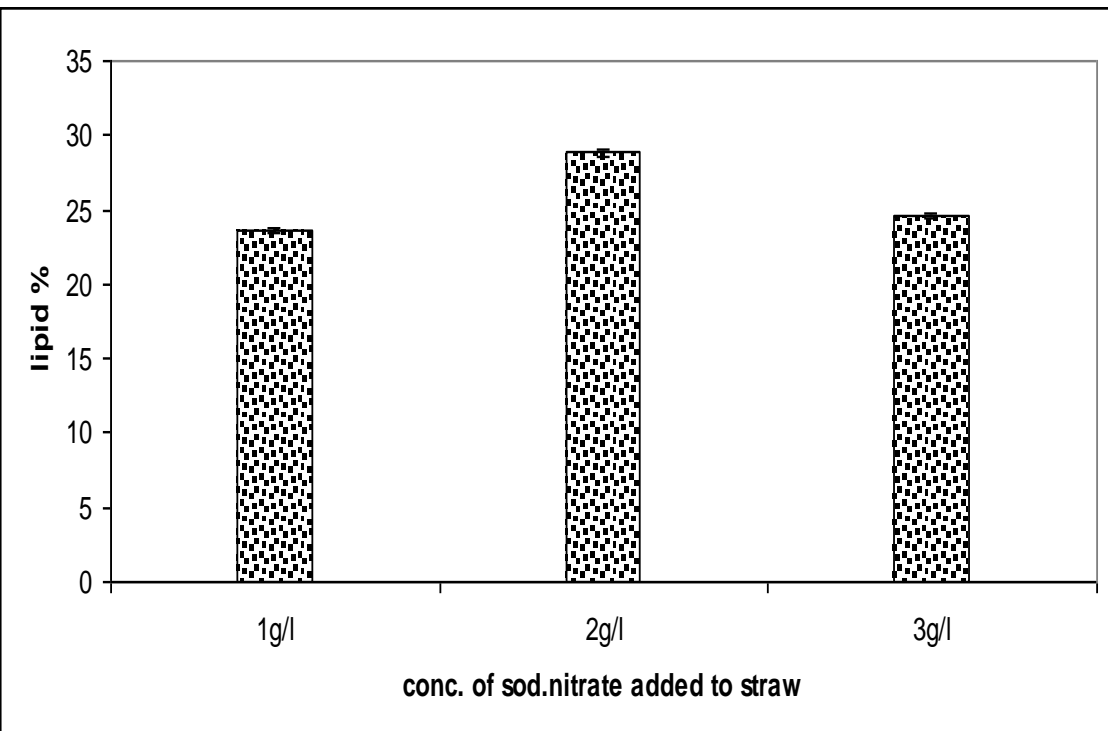

Fig. 11. The relation between different concentrations of $\mathrm{NaNO}_{3}$ was added to wheat straw and lipid percentage data plotted are means \pm SD of three replicates per test.

Lipid analysis using FTIR

The Fourier transform infrared (FTIR) spectra of triglycerides are presented in Fig. $12 \& 13$ which illustrate the spectra of lipid extracted from F.oxysporum using both el-ghasheem and wheat straw media. Significant peaks were created between 1670 to $1820 \mathrm{~cm}^{-1}$, confirming the presence of carbonyl groups. There are peaks between 2850 to $2929 \mathrm{~cm}^{-1}$ that show presence of methyl groups. All of the mentioned peaks confirm that the produced oil can be converted to biodiesel potentially (Lin-Vien,1991; Elumalai et al., 2011). After transesterification of fungal lipids, FTIR spectrum was recorded in the Fig. 14 which showed peak at $1197 \mathrm{~cm}^{-1}$, confirming presence of $\mathrm{C}-\mathrm{O}$ and at $1436 \mathrm{~cm}^{-1}$ which also confirm the presence of (CO)-O- $\mathrm{CH}_{3}$. These peaks confirmed the conversion of fungal lipids into biodiesel. 


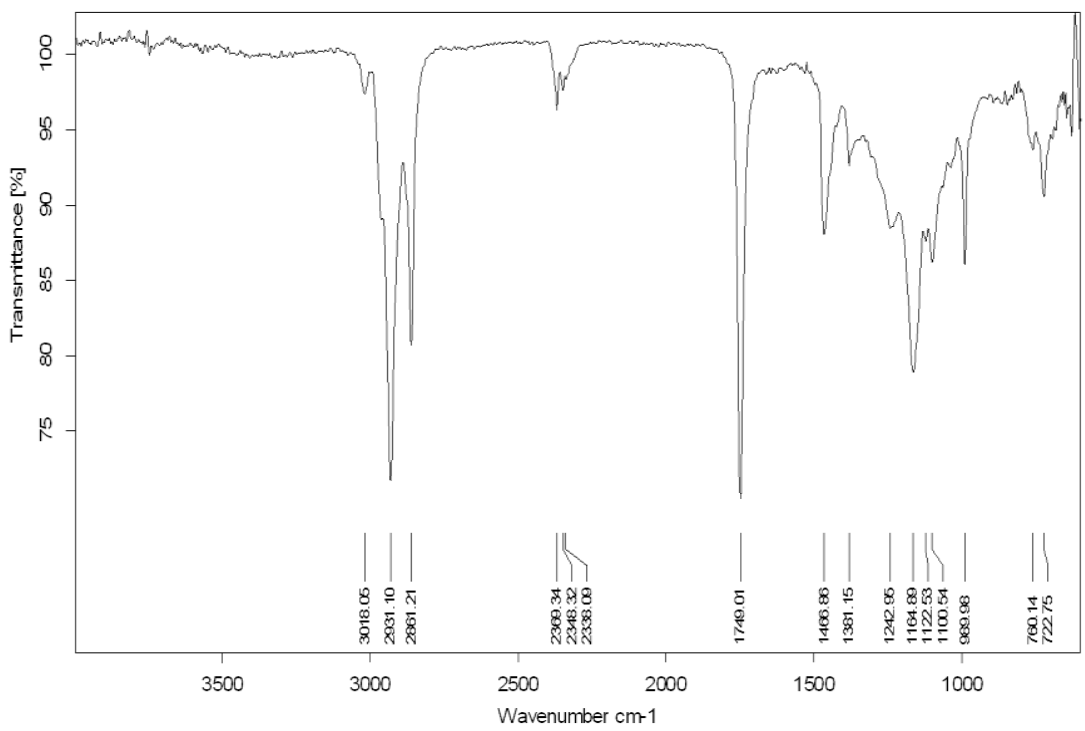

Fig.12. FTIR spectrum of lipid extracted from F.oxysporum using $125 \mathrm{gl}^{-1}$ elghasheem plus $0.1 \mathrm{gl}^{-1} \mathrm{NaNO}_{3}$ medium .

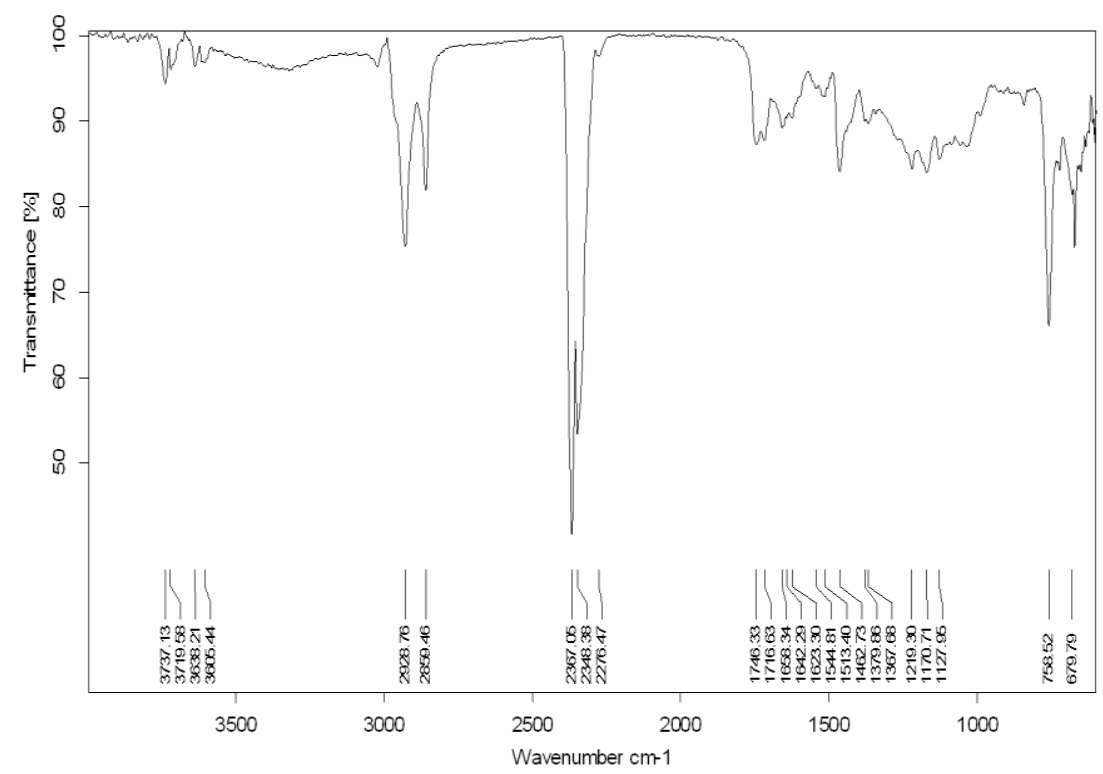

Fig. 13. FTIR spectrum of lipid extracted from F.oxysporum using $5 \mathrm{~g}$ wheat straw plus $50 \mathrm{ml} \mathrm{NaNO}\left(2 \mathrm{gl}^{-1}\right)$ medium.

Egypt. J. Bot. 56, No. 3 (2016) 


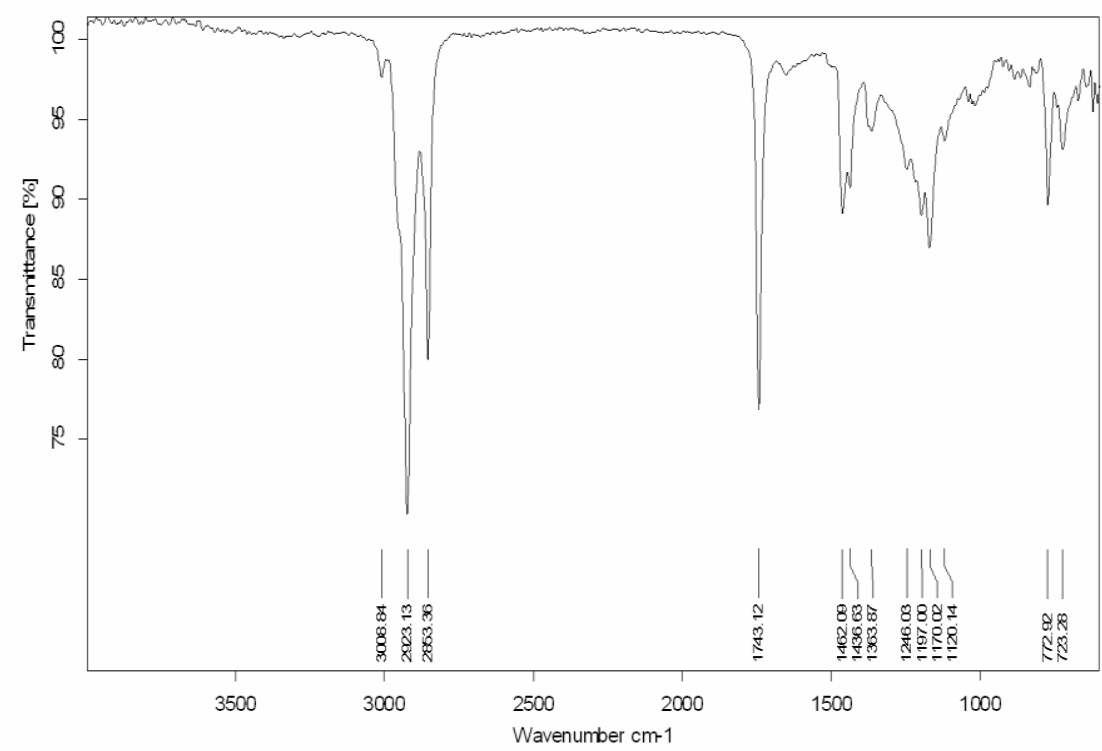

Fig.14. FTIR spectrum of F.oxysporum biodiesel .

Determination of fatty acids profile by $G C-F I D$

The fungal SCOs (Single cell oils) in the present study were found to contain a high fraction of saturated, and monounsaturated fatty acids which is considered a potential feature to indicate the fuel quality of fungal based diesel. Among saturated fatty acids, high amount of palmitic acid (C16:0) and significant amount of stearic acid (C18:0) were observed in the lipid profile of F.oxysporum. Among monounsaturated fatty acids, oleic acid (C18:1) was shown to be dominant in SCOs of F.oxysporum. Fungal SCOs usually differ from most vegetable oils in being rich in PUFAs (polyunsaturated fatty acids) and hence are mainly exploited for PUFA production (El-haj et al., 2015). In the present study, the major PUFA member was determined to be linoleic acid (C18:2). Results are represented in the Fig. 15 and Table 2.

TABLE 2. GC analysis of fatty acid methyl esters extracted from F.oxysporum

\begin{tabular}{|l|c|c|c|}
\hline S.No. & Run Time (min.) & Formula & Compound \\
\hline 1. & 36.270 & $\mathrm{C} 16: 1$ & Palmitoleate \\
2. & 36.933 & $\mathrm{C} 16: 0$ & Palmitate \\
3. & 40.686 & $\mathrm{C} 18: 2 \mathrm{n} 6 \mathrm{c}$ & Linoleate \\
4. & 40.952 & $\mathrm{C} 18: 1 \mathrm{n} 9 \mathrm{c}$ & Oleate \\
5. & 41.559 & $\mathrm{C} 18: 0$ & Steareate \\
6. & 49.688 & $\mathrm{C} 22: 0$ & Beheneate \\
7. & 54.574 & $\mathrm{C} 23: 0$ & Tricosanoate \\
\hline
\end{tabular}

Egypt. J. Bot. 56, No. 3 (2016) 


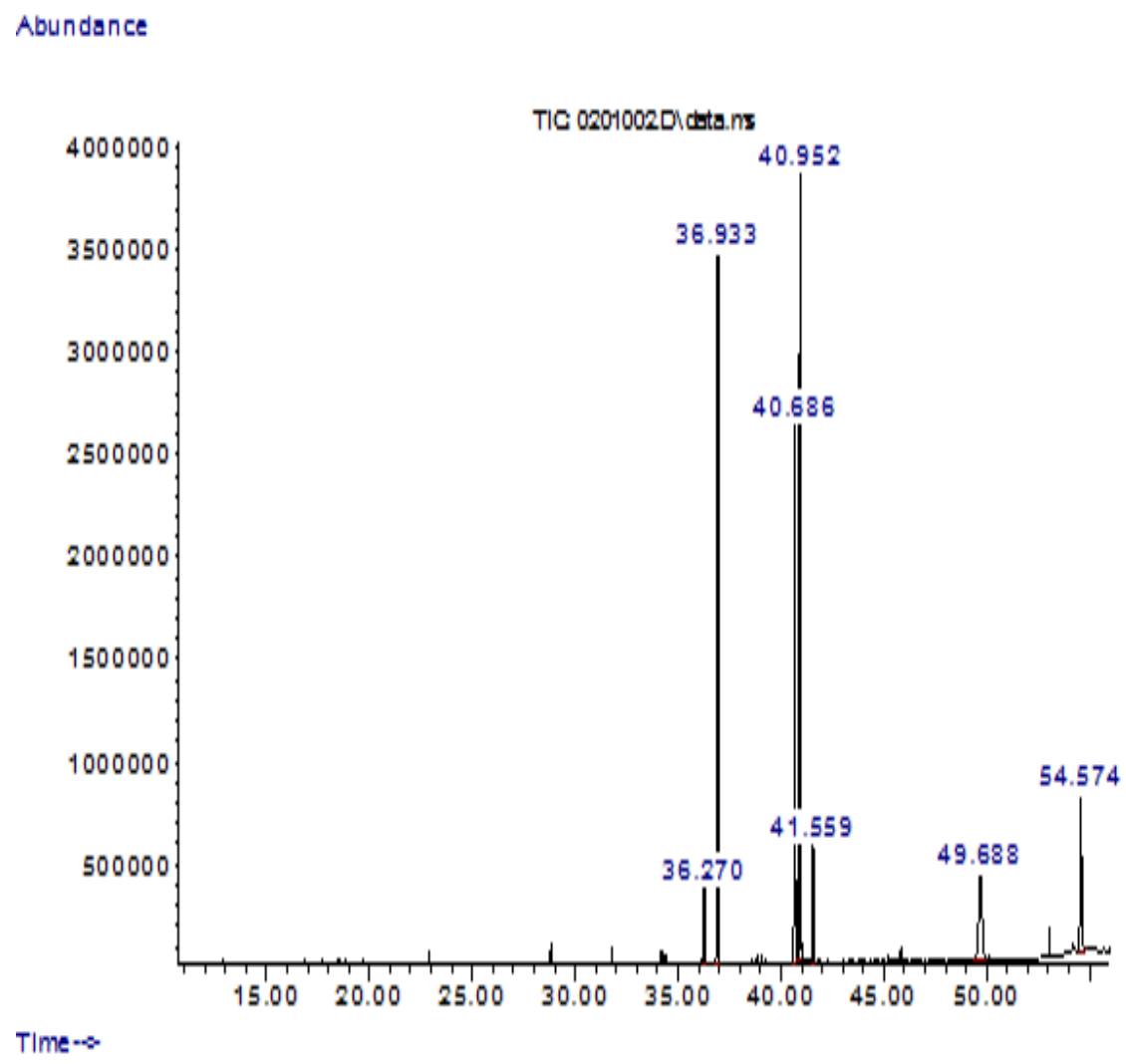

Fig. 15. GC chromatogram of fatty acid methyl esters extracted from of $F$.oxysporum

\section{Conclusion}

The filamentous fungus Fusarium oxysporum AUMC 3224 is not only able to generate significant amounts of mycelia and lipid, but can also convert different types of agricultural wastes into high amounts of triglycrides which are effectively transesterified into significant amount of biodiesel, indicating the promising future of utilizing agricultural residues for economical biodiesel production using F.oxysporum. The use of these residues for biodiesel production would aggregate the value of agricultural wastes, reduce the environmental pollution and also reduce the cost of biodiesel. Finally, production of biodiesel at low cost opens the door for replacing fossil fuel and avoiding its environmental, health, and economic problems.

Egypt. J. Bot. 56, No. 3 (2016) 
BIODIESEL PRODUCTION FROM AGRICULTURAL AND AGROINDUSTRIAL . . 749

\section{References}

Abu-Elreesh, G. and Abd-El-Haleem D. (2013) An effective lipid-producing fungal sp. strain DGB1 and its use for biodiesel production. African Journal of Biotechnology, 12(34), 5347-5353.

Abu Yousuf, Mozammel Hoque, M. Asraful Jahan and Domenico Pirozzi. (2012) Technology and engineering of biodiesel production: a comparative study between microalgae and other non-photosynthetic oleaginous microbes. International Review of Chemical Engineering, 4(6), 624-628

Ageitos J., Vallejo J., Veiga-Crespo P. and Villa T. (2011) Oily yeasts as oleaginous cell factories. Applied Microbiology and Biotechnology, 90, 1219-1227.

Ayhan D. (2009) Progress and recent trends in biodiesel fuels. Energy Conversion and Management, 50, 14-34.

Azócar, L., Ciudad G., Heipieper H. and Navia R. (2010) Biotechnological processes for biodiesel production using alternative oils. Applied Microbiology and Biotechnology, 88(3), 621-636.

Baqir, S. N., Khurshid H., Farooq A. K., Dilnawaz S., Zafar A. M. (1997) Production of lipids by fermentation preliminary report. Journal of Islamic Academy of Sciences, 10 (1), 13-18.

El-haj, M., Olama Z. and Holail, H. (2015) Single cell oil of oleaginous fungi from Lebanese habitats as a potential feed stock for biodiesel. International Journal of Current Microbiology and Applied Sciences, 4(7), 11-34

Elumalai, S., Sakthivel, R. and Ganesh, K. S. (2011) Ultra structural and analytical studies of biodiesel producing microalgae (Chlorella vulgaris and Senedesmis sp.) collected from Tamil Nadu. Current Botany, 2, 19-25.

Folch, J., Lees, M. and Stanley, GHS. (1957) A simple method for the isolation and purification of total lipids from animal tissues. Journal of Biological Chemistry, 226, 497-509.

Gui M.M., Lee K.T. and Bhatia S. (2008) Feasibility of edible oil vs. non-edible oil vs. waste edible oil as biodiesel feedstock. Energy, 33(11), 1646 - 1653.

Huang, J.Z., Shi, Q.Q., Zhou, X.L., Lin, Y.X., Xie, B.F. and Wu, S.G. (1998) Studies on the breeding of Mortierella isabellina mutant high producing lipid and its fermentation conditions. Microbiology, 25, 187-191.

Knothe, G. (2008) "Designer" Biodiesel: Optimizing fatty ester composition to improve fuel properties. Energy and Fuels, 22, 1358-1364. 
La, R. (2005) World crop residues production and implications of its use as a biofuel. Environment International, 31(4), 575-584

Liang, M. and Jiang, J. (2013) Advancing oleaginous microorganisms to produce lipid via metabolic engineering technology. Progress in Lipid Research., 52, 395-408.

Lin-Vien, D., Colthup, N. B., Fateley, W. G. and Grasselil, J. G. (1991) The Handbook of Infrared and Raman Characteristic Frequencies of Organic Molecules (vol.1). United Kingdom : Academic Press.

Madho, S. and Davis, S.B. (2008) Review of proven technologies available for the reduction of raw sugar colour. Proceedings of the South African Sugar Technologists' Association, 81, 165-183.

Matthew, N. C. (2008) Algae as a renewable source for liquid fuel, biodiesel. Guelph Engineering Journal, 1, 2 - 7.

Miao, X. and Wu, Q. (2006) Biodiesel production from heterotrophic microalgal oil. Bioresource technology, 97, 841-846.

Nithya, D. M. and Velayutham, P. (2011) Biodiesel production from fungi. Indian Journal of Natural Sciences, 1(5), 275- 281.

Ratledge, C. (1991) Microorganisms for lipids. Acta Biotechnologica, 11, 429-438.

Ratledge, C. (2004) Fatty acid biosynthesis in microorganisms being used for single cell oil production. Biochimie, 86, 807-815.

Ratledge, C. and Wynn, J.P. (2002) The biochemistry and biotechnology of lipid accumulation in oleaginous microorganisms. Advances in Applied Microbiology , 51, $1-51$

Somasekhar, D., Venkateshwaran, G., Sambaiah, K. and Lokesh, B.R . (2003) Effect of culture conditions on lipid and gamma-linoleic acid production by mucoraceous fungi. Process Biochemistry, 38, 1719-1724.

Subramaniam, R., Dufreche, S., Zappi, M. and Bajpai, R. (2010) Microbial lipids from renewable resources: production and characterization. Journal of Industrial Microbiology and Biotechnology, 37, 1271-1287

Takeno, S., Sakuradani, E., Tomi, A., Inohara-Ochiai, M., Kawashima, H. and Shimizu, S. (2005) Transformation of oil-producing fungus, Mortierella alpina 1 S-4, using zeocin, and application to arachidonic acid production. Journal of Bioscience and Bioengineering, 100, 617-622.

Thai, CCD and Doherty WOS. (2012) Characterisation of sugarcane juice particles that influence the clarification process. Proceedings of the Australian Society of Sugar Cane Technologists, 34, 1-9

Egypt. J. Bot. 56, No. 3 (2016) 
BIODIESEL PRODUCTION FROM AGRICULTURAL AND AGROINDUSTRIAL ... 751

Venkata, S. G. and Venkata, M. S. (2014) Lipid accumulation for biodiesel production by oleaginous fungus Aspergillus awamori: Influence of critical factors. Fuel, 116, 509-515

Vicente, G., Bautistaa, L., Rodrígueza, R., Gutiérreza, J., Sádabaa, I., RuizVázquezb, M., Torres-Martínezb, S. and Garreb, V. (2009) Biodiesel production from biomass of an oleaginous fungus. Biochemical Engineering Journal, 48, 22-27.

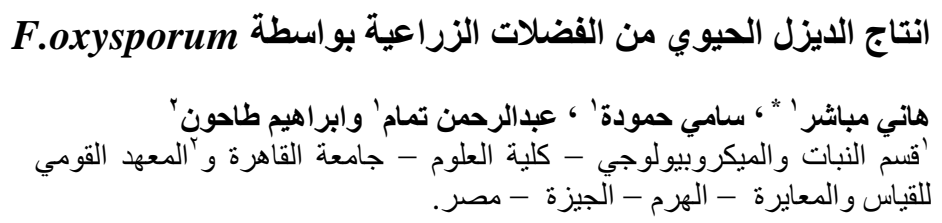

كان الهدف من هذا البحث هو دراسة انتاج الديزل الحيوي بواسطة فطر

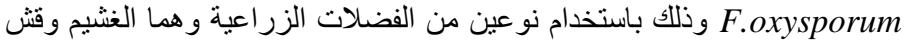

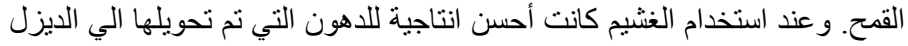

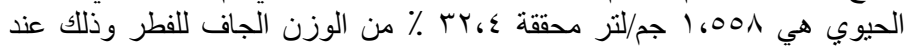

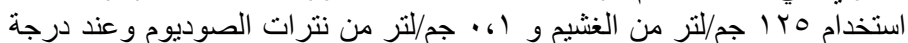

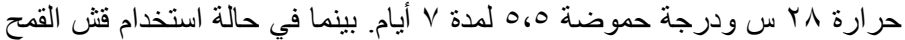

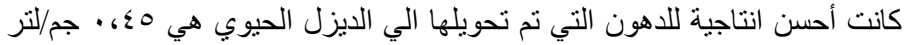

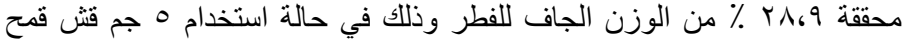

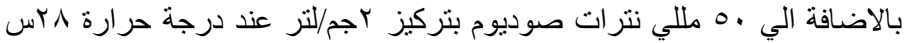

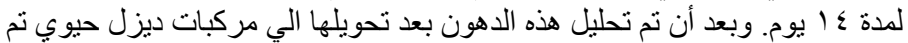

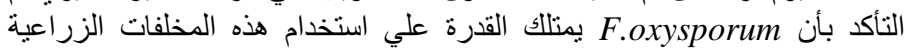
لانتاج وقود حيوي واستخدامه بديلا عن الوقود الأحفوري. 
M.H.MOUBASHER et al .

Egypt. J. Bot. 56, No. 3 (2016) 